\author{
RESEARCH SEMINAR IN INTERNATIONAL ECONOMICS \\ Department of Economics \\ The University of Michigan \\ Ann Arbor, Michigan 48109-1220 \\ SEMINAR DISCUSSION PAPER NO. 235

\section{ESTIMATES OF THE ELASTICITIES OF SUBSTITUTION BETWEEN IMPORTS AND HOME GOODS \\ FOR THE UNITED STATES: REPLY}

$$
\text { by }
$$

Clinton R. Shiells

U.S. Department of Labor

Robert M. Stern

The University of Michigan and Brandeis University

Alan V. Deardorff

The University of Michigan

December 20, 1988

Address correspondence to:

Clinton R. Shiells

Office of Foreign Economic Research Bureau of International Labor Affairs U.S. Department of Labor

Washington, D.C. 20210 



\section{Introduction}

Following the two-stage budgeting approach in Deaton and Muellbauer (1980) and Deardorff and Stern (1986), the econometric estimates of import-demand elasticities in Shiells, Stern, and Deardorff (1986) were done holding within-group expenditure constant. Based on this assumption, the correct way to compute the rate at which imports displace the competing home good following the imposition of a tariff is to infer the cross-price elasticity of home-good demand from estimated import-demand elasticities using the group budget constraint. Employing this method, we show below that the increase in spending on home goods implied by our estimates must be less than the dollar-for-dollar assumption would imply. Rousslang's comparison of our estimates with the dollar-for-dollar approach is based on the mistaken assumption that our estimates were obtained holding total expenditure, rather than within-group expenditure, constant.

Those who wish to use the partial elasticity estimates in Shiells et al. (1986) for other purposes should also take into account the fact that they were based on this assumption of constant within-group expenditure. Ideally, the total elasticity of demand for imports should be constructed by combining these estimates with other estimates of the demand elasticities of the composites of home and imported goods. We show below the formula for this construction. However, for situations in which these composite elasticities are not available, the alternative exists of assuming that preferences for the composites are Cobb-Douglas. In this case our constant-expenditure elasticities can be used directly as total elasticities of demand for imports. 


\section{Substitution Terms for Goods in other Industries}

To establish the plausibility of the dollar-for-dollar method Rousslang shows that it follows from two assumptions: that expenditure on the import comprises a small share of domestic income; and that the substitution effect between home and imported goods is large relative to the substitution effect between the imported good and other goods.

The latter assumption is equivalent to setting substitution effects between goods in different industries to zero. This is a very strong assumption. In contrast, in our own approach, by assuming weak separability we were able to drop prices of goods in other industries from the import-demand equation without forcing substitution effects between goods in different industries to be zero.

\section{Total vs. Partial Elasticities}

To help policy modelers use our elasticity estimates correctly, this section gives formulas for total elasticities (which hold total expenditure $Y$ constant) in terms of partial elasticities (which hold group expenditure $e_{i}$ constant).

Using the model and notation in our paper (see pp. 499-501) and under the assumption that subutility functions $x_{i}$ are homogeneous of degree one, total elasticities can be obtained from partial elasticities using the following equations: ${ }^{1}$

(1) $N_{j k}^{i}=n_{j k}^{i}+\theta_{i}^{k}\left(1+n_{x p}^{i}\right)$

$$
(i=1, \ldots, r ; j, k=H, M)
$$

(2) $N_{j Y}^{i}=n_{X Y}^{i}$

$$
(i=1, \ldots, I ; j=H, M) \text {; }
$$

where $\theta_{i}^{k}=p_{i}^{k} q_{i}^{k} / e_{i}$ and elasticities in equations (1) and (2) are defined as follows :

${ }^{1}$ See Caves and Christensen (1979, p. 10) for a demonstration of equation (1). The derivation of equation (2) is similar. 


$$
\begin{aligned}
& \mathrm{N}_{j H}^{i}=\left.\frac{\partial q_{i}^{j}}{\partial_{p_{i}^{H}}^{H}} \frac{p_{i}^{H}}{q_{i}^{j}}\right|_{p_{1}^{H}, p_{1}^{M}, \ldots, p_{i-1}^{M}, p_{i}^{M}, \ldots, p_{r}^{M}, Y} \\
& N_{j M}^{i}=\left.\frac{\partial q_{i}^{j}}{\partial p_{i}^{M}} \frac{p_{i}^{M}}{q_{i}^{j}}\right|_{p_{1}^{H}, p_{1}^{M}, \ldots, p_{i}^{H}, p_{i+1}^{H}, \ldots, p_{z}^{M}, Y} \\
& \mathrm{~N}_{j Y}^{i}=\left.\frac{\partial q_{i}^{j}}{\partial y} \frac{Y}{q_{i}^{j}}\right|_{p_{1}^{y}, \ldots, p_{y}^{M}} .
\end{aligned}
$$

\section{Partial Elasticities}

$$
\tilde{n}_{j H}^{i}=\left.\frac{\partial q_{i}^{j}}{\partial p_{i}^{H}} \frac{p_{i}^{z I}}{q_{i}^{j}}\right|_{p_{i}^{M}, e_{i}} \quad n_{j M}^{i}=\left.\frac{\partial q_{i}^{j}}{\partial p_{i}^{M}} \frac{p_{i}^{M}}{q_{i}^{j}}\right|_{p_{i}^{H}, e_{i}}
$$

\section{Composite-Good Elasticities}

$$
n_{X P}^{i}=\left.\frac{\partial X_{i}}{\partial P_{i}} \frac{P_{i}}{X_{i}}\right|_{P_{1}, \ldots, P_{i-1}, P_{i+1}, \ldots, P_{r}, Y} n_{X Y}^{i}=\left.\frac{\partial X_{i}}{\partial Y} \frac{Y}{X_{i}}\right|_{P_{1}, \ldots, P_{r}},
$$

and $P_{i}\left(p_{i}^{M}, p_{i}^{M}\right)$ is a price aggregator.

If reliable estimates of composite-good elasticities are unavailable, one can assume that the first-stage utility function is Cobb-Douglas, so that group expenditure is a constant share of total expenditure. Under this assumption, partial and total price elasticities are equal since $n_{X P}^{i}=-1$.

In any event, total substitution elasticities can be inferred from total demand elasticities and the Slutsky equation:

$$
N_{M Y Y}^{i}=\theta_{i}^{H}\left(\Sigma_{i}-N_{M Y}^{i}\right) \text {, }
$$

where $\Theta_{i}^{H}=p_{i}^{H} q_{i}^{H} / Y$ and $\Sigma_{i}$ is the Allen (1938) elasticity of substitution between imports and home goods in group $i$, holding total utility (u) and prices of goods in all other groups constant. 
IV. Comparison with the Dollar-for-Dollar Assumption

To compare results in our paper with the dollar-for-dollar assumption, Rousslang expresses the ratio of changes in spending on domestic goods and imports (net of tariff) resulting from the imposition of a tariff as follows: $d\left(p_{i}^{H z} q_{i}^{H z}\right) / d t$

$$
\left.\frac{d\left(p_{i}^{M O} q_{i}^{M}\right) / d t}{d \theta_{i}^{M}} / \theta_{i}^{M}\right)\left(n_{H M}^{i} / n_{M M}^{i}\right) \text {, }
$$

where $p_{i}^{M}=p_{i}^{M O}(1+t), P_{i}^{M O}$ is the (exogenous) world import price, and $t$ is the tariff rate.

At the bottom of page four, Rousslang sets income effects to zero to estimate cross-price elasticity, $\mathfrak{n}_{H M}^{i}$, by assuming that spending on imports in an industry is small compared to total income. Given that group expenditure is held constant, it is a mistake to drop income effects because spending on imports is not necessarily small compared to group expenditure.

Bearing in mind that only $(n-1)$ demands can be estimated independently if there are $n$ goods due to the budget constraint (see Christensen and Manser (1977, p. 39)), we estimated only the import-demand elasticities. Home-good demand-elasticity estimates can be inferred from these simpiy by using the group budget constraint:

$$
e_{i}=p_{i}^{\mathbf{H}} q_{i}^{H z}+p_{i}^{M} q_{i}^{M}
$$

Differentiating the budget constraint partially with respect to import price $\mathrm{p}_{i}^{M}$ (holding $\mathrm{p}_{i}^{\mathrm{H}}$ and $e_{i}$ fixed) and rearranging yields: ${ }^{2}$

(4) $n_{\text {HM }}^{i}=-\left(\theta_{i}^{M} / \theta_{i}^{H}\right)\left(1+n_{M M}^{i}\right)$.

Combining equations ( 3 ) and (4):

${ }^{2}$ Similarly, $n_{\text {fH }}^{i}$ and $n_{\text {fro }}^{i}$ can be estimated using:

$$
\begin{aligned}
& n_{H H}^{i}=-\left(\theta_{i}^{H}+\theta_{i}^{M} z_{M H}^{i}\right) / \theta_{i}^{H} \\
& n_{H_{0}}^{i}=\left(1-\theta_{i}^{M} \eta_{H_{0}}^{i}\right) / \theta_{i}^{H} .
\end{aligned}
$$


(5) $\frac{d\left(p_{i}^{H} q_{i}^{H}\right) / d t}{d\left(p_{i}^{M 0} q_{i}^{M}\right) / d t}=-\left(1+\eta_{M M}^{i}\right) / z_{M M}^{i}$.

From equation (5), it is clear that home-good spending falls by less than a dollar in response to a dollar increase in import spending (net of the tariff) if and only if the (uncompensated) own-price elasticity of import demand is negative. 
Allen, R.G.D., Mathematical Analysis for Economists, London: MacMillan and Company, Ltd., 1938.

Caves, Douglas W. and Laurits R. Christensen, "Econometric Analysis of Residential Time-of-Use Electricity Pricing Experiments, " Social Systems Research Institute, Workshop Paper 7932, University of Wisconsin-Madison.

Christensen, Laurits R. and Marilyn E. Manser, "Estimating U.S. Consumer Preferences for Meat with a Flexible Utility Function," Journal of Econometrics 5 (January 1977): 37-53.

Deaton, Angus and John Muellbauer, Economics and Consumer Behavior, Cambridge: Cambridge University Press, 1980.

Deardorff, Alan V. and Robert M. Stern, The Michigan Model of World Production and Trade, Cambridge: MIT Press, 1986.

Rousslang, Donald J., "Estimates of the Elasticities of Substitution between Imports and Home Goods for the United States: Comment, "mimeo (February 1987).

Rousslang, Donald J. and Stephen Parker, "Cross-Price Elasticities of U.S. Import Demand," Review of Economics and Statistics 66 (August 1984): 518-523.

Shiells, Clinton R., Robert M. Stern, and Alan V. Deardorff, "Estimates of the Elasticities of Substitution between Imports and Home Goods for the United States," Weltwirtschaftliches Archiv 122 (1986): 497-519. 


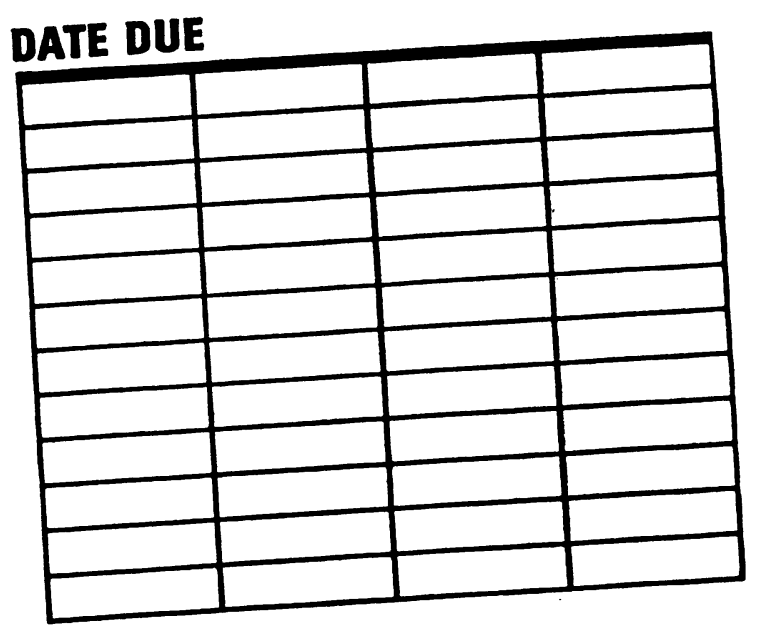


